\title{
Body condition is negatively associated with infection with Syngamus trachea in the ring- necked pheasant (phasianus colchicus)
}

by Gethings, O.J., Sage, R.B., Morgan, E.R. and Leather, S.R.

Copyright, Publisher and Additional Information: This is the author accepted manuscript. The final published version (version of record) is available online via Elsevier Please refer to any applicable terms of use of the publisher. 
1 Body condition is negatively associated with infection with Syngamus trachea in the Ring-

2 necked Pheasant (Phasianus colchicus).

3 O J Gethings ${ }^{1}$, R B Sage $^{2}$, E R Morgan ${ }^{3}$ and S R Leather ${ }^{1}$

$4{ }^{1}$ Department of Crop \& Environment Sciences, Harper Adams University, Edgmond, Newport,

5 TF10 8NB UK; ${ }^{2}$ Game \& Wildlife Conservation Trust, Burgate Manor, Fordingbridge, SP6

$6 \mathrm{IEF}, \mathrm{UK} .{ }^{3}$ University of Bristol, School of Veterinary Sciences, Langford House, Langford,

$7 \quad$ North Somerset, BS40 5DU.

8 Summary

9 The role that parasites play in regulating animal populations is debated, however recent research hints 10 at their pervasiveness among free-living animal populations. Parasites exert both direct and indirect

11 effects on host populations, and can act to regulate populations. The Ring-necked pheasant is an 12 important game-bird species in the UK, and large numbers of birds are released annually. The impact 13 of the ubiquitous tracheal nematode, Syngamus trachea on pheasant populations through effects on 14 host condition was assessed on two pheasant estates in the south west of England. Pheasants infected 15 with $S$. trachea demonstrated a significant reduction in host condition compared with uninfected 16 controls, with as few as one pair of worms per bird. Although there was no difference in worm 17 burden between sexes, analysis of regression slopes revealed there was a significant difference 18 between sexes in the magnitude of the effect of increasing worm burden on host condition, with 19 detectable effects observed in hosts with one and three pairs of worms for males and females 20 respectively. The observed reductions in host condition in birds with even sub-clinical infections 21 could be the cause of poor reproductive success and survival of pheasants post-release.

\section{Keywords}

23 Phasianus colchicus; Pheasant; Body condition; Gapeworm; Syngamus trachea; Reproduction 
25 Parasites are well known to play an important role in regulating host population dynamics (Tompkins 26 \& Begon, 1999; Irvine et al., 2006; Dunn et al., 2012; Watson, 2013; Granoth-Wilding et al., 2015), 27 although there has been some debate as to the relative importance of predators compared with parasites (Irvine, 2000; Moss \& Watson, 2001). Recent research however, has demonstrated that parasites are as, if not more, important than predators in regulating host populations (Watson, 2013). Parasites can have direct impacts on host populations through increases in morbidity and mortality, and they can also indirectly affect host populations through reductions in fecundity (Hudson, 1986; Dunn et al., 2012; Granoth-Wilding et al., 2015). Despite this, very little published research exists on the effects of parasite species on condition and host population dynamics in the ring-necked pheasant. One of the few studies by Draycott et al. (2002) assessed the effects of Syngamus trachea and Heterakis gallinarum on pheasant populations and concluded that infection with these species did not negatively affect host body condition. One major issue with this study is that body condition was assessed in April, whereas the infectious stages of $S$. trachea, and therefore infection pressure do not reach their peak until around June/July (Gethings et al., 2015). A similar issue was observed by Irvine et al. (2006). Previous studies failed to find any effect of gastrointestinal nematodes on host condition in Reindeer populations in the High Arctic, however Irvine et al. (2006), through the use of delayed-release anthelmintic boluses, demonstrated reductions in host fitness in winter. Reindeer populations were sampled previously when populations were more accessible, which highlights the importance of timing research protocols to account for seasonal dynamics in the transmission of parasites, and therefore any parasite-mediated effects. Reproductive success of released ring-necked pheasants is generally poor compared with their 'wild' counterparts (Leif, 1994), but it is currently unclear as to why this is the case (Leif, 1994; Draycott et al., 2000; Millan et al., 2002; Draycott et al., 2006; Villanua et al., 2006). A number of factors such 
as increased parasitic worm infections and reduced food availability/quality are believed to be major components governing life-history traits in game birds (Hudson et al., 1992). Syngamus trachea, for example, is a parasitic-tracheal nematode that commonly affects managed pheasant and poultry populations. Morbidity rates are generally very high, particularly when birds are managed under high stocking densities and when proper sanitary measures are not incorporated into management programs (Gethings et al., 2015). There is marked pathology associated with syngamosis (Fernando et al., 1971; Nevarez et al., 2002; Atkinson et al., 2008) and mortality rates of affected birds can be as high as $80 \%$ (Wojcik et al., 1999). Experimental infections with $S$. trachea have demonstrated negative associations between larval challenge and weight gain and condition. Hwang (1964) experimentally infected turkey poults with varying numbers of $S$. trachea-infected earthworms to observe their effect on weight gain and packed cell volume (PCV). Significant differences were identified in weight gain between birds infected with an average of 0.2 worms $(n=10)$ compared with an average of 55 worms $(n=55)$, with the heavily infected group gaining an average of $51 \mathrm{~g}$ compared with 1482g for the lightly infected group (Hwang, 1964). This significant effect on weight gain and condition could potentially influence fecundity directly through parasite-mediated competition for resources or indirectly if the host invests more resources into mounting an immune response (Delahay et al., 1995; Shutler et al., 2012). Indeed, Draycott et al. (2006) demonstrated increased breeding success in pheasants treated with Flubendazole, which suggests a possible relationship between fecundity and parasitic infection in the ring-necked pheasant.

Similarly, other studies have demonstrated significant negative parasite-mediated effects on host fitness. Many of these associations are however, correlational, and it is often difficult to disentangle cause and effect in the parasite-host relationship. Tompkins et al. (2000), demonstrated a negative relationship between the caecal nematode $H$. gallinarum and body condition in partridges. More relevant perhaps, is the negative association identified between $H$. gallinarum and body mass, breast muscle mass and cloacal fat in ring-necked pheasants (Sage et al 2002). 
The aim of the present study was to evaluate what effect, if any, significant infections with the nematode, Syngamus trachea have on pheasant body condition under natural circumstances.

\section{Materials and method}

\subsection{Study sites}

Two pheasant estates were selected in the South West of England due to regular problems with clinical syngamosis, as reported by managers. Site 1 was located approximately at grid reference ST 9750239837 and consisted of seven release pens. Site 2 was situated approximately at grid reference SU 1776930326 and similarly consisted of seven release pens. Both sites release $\sim 15,000$ birds annually, undertake thorough predator control measures and provide supplementary grain via feed hoppers. Anthelmintic treatment (Flubendazole - at manufacturers dosage recommendations) ceased after birds were released in June 2015. Sites were matched in order to ensure that any effects on body condition would be parasite-mediated and not a result of intra/inter specific competition for food resources or other environmental factors.

\subsection{Carcass recovery}

90 One hundred and eighty adult pheasants were recovered following release from June 2015 through

91 April of 2016. Birds were recovered by professional game managers, either as part of crop-protection programs or were shot during the shooting season. Pheasants were either shot whilst flying, or occasionally found dead upon the estate $(n=4)$. Carcasses that had been scavenged were not included in the analysis and recovered birds were examined for non-parasite related disease that could influence the results. Carcasses were processed immediately upon recovery and assessed for the presence of $S$. trachea, Ascaridia galli and $H$. gallinarum by dissection of the trachea, 
gastrointestinal tract and abdominal cavity and caeca respectively. Other nematode species were recorded but were not differentiated by species, as they were too few in number. In two instances, severely emaciated pheasants with bulbous, fluid-filled intestines consistent with clinical hexamitiasis and confirmed by the presence of motile protozoa on wet slide preparation were recovered. These birds were excluded from the analyses as they were found to be free of nematode infection, but are mentioned in the discussion.

\subsection{Worm recovery and body condition assessment}

Adult pheasants were weighed to the nearest $0.1 \mathrm{~g}$ using a digital weighing scales and tarsal length was measured using a digital calliper with accuracy to $0.01 \mathrm{~mm}$. A body condition index was then obtained by dividing body mass by tarsal length (Yom-Tov, 2001), which controlled for body size.

\subsection{Statistical analysis}

To determine whether the data were aggregated, adult worm counts were compared with an estimated Poisson distribution $\left(\mu=\sigma^{2}\right)$ with $n-1$ d.f. using the chi.sq test function in $\mathrm{R}$ available in the MASS package. Data were then compared with both an estimated Poisson and a Negative Binomial distribution using the fitdistr function (fitdistrplus package) and goodness of fit was assessed using Maximum Likelihood Estimation using AIC as a determinant. As the number of factors in each model were equal, the model with the lowest AIC score was considered a better fit. All data were analysed using $R$ for Macintosh. The effect of parasite burden on host body condition was assessed using ordinary least-squares regression using $\log (n+1)$ transformed parasite count data. Though the inclusion of the four dead-found birds could be a potential confounder, there was no change in model accuracy when they were excluded. Non-constant error variance was assessed using the Breusch-Pagan test and 'ratio' data were transformed to the appropriate power transformation 
$121\left(y^{\wedge} 0.15\right)$. The transformed data were then assessed for non-constant error variance, which confirmed 122 that the power transformation was successful $\left(x^{2}=0.54, d f=1, p=0.51\right)$. Differences in parasite 123 burden between sexes (including zero counts) were assessed using Welch's t-test for unequal 124 samples.

\section{Results}

Parasite count data were significantly different from the estimated Poisson distribution $\left(x^{2}=2175\right.$, d.f $129=153, p=<0.001)$ and comparison of models demonstrated the data were aggregated, and consistent 130 with the negative binomial distribution $\left(x^{2}=4.87\right.$, d.f $\left.=3, p=0.18\right)$. The overall prevalence of $S$. 131 trachea within this study population was $33 \%$, with $32 \%$ of males ( $n=148, n=48$ infected) and $38 \%$ 132 of females $(n=32, n=12$ infected) being infected with at least 1 pair of worms. Males had a mean $( \pm$ 133 SEM) worm burden of $3.01 \pm 0.54$, and females had a mean $( \pm$ SEM) worm burden of $4.78 \pm 1.68$, 134 however no significant differences were found between sexes in mean worm burden $\left(t^{35.78}=-1.26, p\right.$ $135=0.21)$.

\subsection{Effect of S. trachea on body condition}

Worm burden and the associated effects on pheasant body condition are presented in tables 1 and 2 .

139 The regression of $\log$ parasite burden on body condition revealed a significant inverse relationship 140 between increasing worm burden and body condition in pheasants $\left(F^{3,176}=216.2, R^{2}=0.78, P=<\right.$ 141 0.001). Similarly, the effect of 'sex' was significant (coef $=1.1002, t=2.84, p=0.005)$ with 142 regression slopes of $b=-4.18(95 \% \mathrm{CI}=-4.034)$ and $b=-3.23(95 \% \mathrm{CI}=-2.67)$ for males and

143 females respectively, with slopes being statistically different from each other $\left(t^{176}=2.38, p=0.01\right)$. 
144 Comparison of regression coefficients for minimum worm burden requirements for identifiable 145 reductions in body condition revealed 1 and 3 pairs were required for males (coef $=-1.73, t=-4.69$, $146 p=<0.001)$ and females (coef $=-3.24, t=-2.80, p=0.04)$ respectively. Stepwise deletion of the 147 lowest parasite burdens suggested a 'flattening off' in body condition reduction above 11 worms per 148 bird.

\section{Discussion}

Pheasants infected with Syngamus trachea demonstrated significantly reduced body condition when compared with uninfected birds, and a negative association was identified between the number of $S$. trachea pairs per bird and body condition. This is the first study to observe such profound reductions in host body condition in pheasants naturally infected with S. trachea. Although Hwang et al. (1964) found that infection with $S$. trachea negatively affected weight gain in turkey poults, this was a result of an experimental infection, which does not accurately represent conditions faced by wild birds in terms of encounter rates and parasite load. Similarly, the provision of feed ad libitum in an experimental setting could increase host fitness and enable the production of a stronger immune response compared with birds under natural conditions.

The presence of parasites within these study populations, and the apparent parasite-mediated 161 effects on body condition in post-release adult pheasants could have far-reaching ecological consequences (Delahay et al., 1995). It is well documented that reared pheasants have reduced

163 survival and reproductive success compared with their wild counterparts (Leif, 1994; Draycott et al., 164 2000; Millan et al., 2002; Draycott et al., 2006; Villanua et al., 2006), and the high occurrence of $S$. 165 trachea on pheasant estates could be a significant limiting factor on populations; especially 166 considering that even relatively low numbers of adult worms (well below those at which clinical 167 effects would be observed) are sufficient to produce statistically-significant reductions in host 
condition. Infection with $S$. trachea could affect host populations directly; though parasite or hostmediated reductions in fecundity via responses to developing and established worms; direct competition for resources; or via (hypothetically) disruption of yolk proteins synthesised in the liver. Similarly, indirect effects such as increased predation rates in infected birds could significantly affect population structure and size (Hudson et al., 1992). Though the overall prevalence of disease was low, it may still be exerting a negative pressure on population density if infected hosts have reduced life expectancy compared with uninfected hosts (Anderson, 1995). Indeed, S. trachea has a high mortality rate among juvenile, immunologically-naïve birds (Wojcik et al., 1999) and an increase in parasite-induced mortality in juvenile birds could stabilise the parasite-host interaction by a net loss of parasites from the system (Anderson \& May, 1978). Similarly, as pheasants are extremely susceptible to infection with $S$. trachea, the small proportion of the population susceptible to infection could ensure the persistence of the disease through constant reseeding of infectious stages (Anderson, 1995).

It has been suggested that in order to initiate egg laying, birds must reach a body condition threshold, and that individual host body condition necessarily delays or advances threshold attainment (Drent \& Daan, 1980). For example, parasites that undergo hepato-pulmonary migration and/or cause anaemia via exsanguination compete with the host for protein during the time when energy input is concentrated on egg production (Allander \& Bennett, 1995). Proteins required for yolk production are synthesised within the liver, and the migration of $S$. trachea larvae across the liver parenchyma could impair the production of these proteins (Allander \& Bennett, 1995) thus potentially affecting the onset of laying. Indeed, Jones and Ward (1976) demonstrated that reduced yolk proteins delayed the onset of breeding in Red-Billed Quaeleas. Female pheasants generally lay their eggs between April and June, incidentally when $S$. trachea larval availability is increasing (Gethings et al., 2015). The development and migration of $S$. trachea across the liver parenchyma could disrupt the formation of vital proteins responsible for chick development directly, or indirectly 
193 through competition for host-resources during a period when hen body condition is already reduced 194 (Breitenbach \& Mayer, 1959). Indeed, a number of empirical studies have demonstrated increased 195 survival and reproductive success of birds treated with anthelmintics compared with control birds 196 (Hudson, 1986; Draycott et al., 2006). Woodburn et al. (2002) demonstrated that birds dosed with 197 anthelmintics reared twice as many chicks as un-dosed controls. It is unknown however whether the 198 anthelmintic had a direct effect on breeding success by reducing parasite challenge, or because the 199 treatment was associated with greater bird survival due to reduced predation (Hudson, et al., 1992; 200 Millan, et al., 2002; Woodburn et al., 2002). Similarly, It has been shown in Red Grouse populations, 201 that the number of eggs laid is directly related to host body condition and energy intake in the 202 preceding weeks (Delahay et al., 1995). Delahay et al. (1995) showed that infection with 203 Trichostrongylus tenuis reduced host body condition and could explain poor breeding performance of 204 wild birds. Furthermore, Newborn and Foster (2002) demonstrated that birds with access to grit 205 medicated with Fenbendazole had lower T. tenuis burdens and higher body condition scores than 206 control birds. Interestingly, birds from the treated plots had significantly higher breeding success and 207 reared twice as many chicks as birds from control plots. Chick survival was also significantly greater 208 in treated plots compared with control (Newborn \& Foster, 2002). This, in conjunction with the 209 findings of the present study appear to suggest that parasite infection does indeed have some 210 measurable effect on host populations, whether that be through parasite-mediated competition, 211 reductions in host fecundity mediated by effects on body condition, or other factors is currently 212 unclear. Although currently only speculative, the tentative link between S. trachea infection and 213 pheasant fecundity warrants further consideration. Indeed, Holand et al. (2015), found that house 214 sparrows (Passer domesticus) infected with S. trachea demonstrated reduced reproductive success 215 compared with uninfected controls. They found a reduction in the proportion of eggs within a nest to 216 hatch as faecal egg counts of mothers increased. Similarly, juvenile females with high faecal egg 217 counts demonstrated significantly reduced lifetime reproductive success compared with uninfected 218 birds. 
220 bones, however no quantitative measurements were taken. Although it is not overly surprising, given

221 the highly pathogenic nature of this parasite, that reductions in host body condition were observed, it 222 is surprising that just one pair of worms was associated with an $11 \%$ reduction in body condition 223 compared with uninfected birds. Similarly, these effects were observed in immunologically naïve 224 birds and birds with evidence of previous exposure. The threshold for detectable reductions in host 225 body condition in the present study was particularly low, which could implicate sub-clinical 226 infections as a causal factor of the poor breeding status of released pheasants.

Although there was no detectable difference in mean worm burden between males and females, there was a significant difference in the magnitude of the effect of increasing worm burden. Females, in contrast to males, appear to be able to withstand relatively low worm burdens not suffer any negative effect on body condition below three pairs of worms per host. In contrast, males were often found with single pairs of worms (whereas single infections were not identified in females in this study) and that level of infection already began to affect body condition. The differences between sexes could be explained by differences in resource allocation, and it has been demonstrated that immunocompetence is often sacrificed in favour of the expression of sexual ornaments, particularly in males (Hamilton \& Zuk, 1982; Verhulst et al., 1999). Whether females are able to successfully mount an immune response in the presence of one or two pairs of worms requires further investigation. The apparent "flattening off" of parasite-mediated reductions in body condition above eleven worms per bird can perhaps be attributed to the density-dependent reductions in worm length 239 observed at higher densities (Gethings et al., 2016). Density-dependent reductions in worm length 240 peaked at eleven worms per bird before flattening off. This appears to provide evidence of a reduced 241 per capita effect above the density threshold. 
244 pheasant body condition. This can, however, be explained by the fact that body condition in the 245 Draycott et al (2002) paper was assessed in spring, whereas $S$. trachea larval availability, and 246 therefore clinical cases of syngamosis, generally do not reach their peak until June/July (Gethings et $247 a l ., 2015)$. All birds used in the present study were recovered between March and October, when 248 stress levels are likely to be elevated due to release (Villanua et al., 2006), which also coincides with 249 peak larval availability (Gethings et al., 2015). These conditions are typical of the vast majority of 250 pheasant estates, so results presented here are likely to be comparable with and representative of 251 other intensively reared pheasant populations. Although other parasite species were quantified, there were no similar reductions in pheasant body condition: with the exception of Hexamitia spp., Heterakis gallinarum, along with a few cestoda, were the only other parasite species recovered from these pheasant populations; however, no effect was observed between their densities and body condition, even when total worm burden included S. trachea.

Although it is intuitively likely that the reduction in body condition was a result of significant S. trachea infections, it is difficult to disentangle cause and effect. The problem with cross-sectional studies is that it is difficult to establish whether these negative effects were a result of $S$. trachea infection as opposed to other forms of competition, or, whether birds acquired these parasites because they had reduced condition (Irvine, 200) and less ability to mount an effective immune response. The abundance of supplementary feed, predator control and reduced stocking densities suggests however, that parasites may have been the underlying cause of the observed reductions in body condition.

263 Birds are known to lose a considerable amount of body condition during egg laying and incubation 264 (Breitenbach \& Mayer, 1959), however, the reductions in body condition in infected birds were still apparent when compared with uninfected birds, which would likely be facing similar environmental stressors. 
270 worm burden on adult pheasant condition, with females able to withstand higher worm burdens

271 before suffering any negative effects. Similarly, the results of the present study, in conjunction with 272 the findings of Sage et al. (2002) demonstrate significant parasite-mediated effects on pheasant 273 condition in birds following release and could be the cause for poor breeding success. However, it 274 should be noted that these birds were examined out of the breeding season, and subsequent stress and 275 alternative resource allocation during the breeding season could reduce this threshold in female 276 pheasants.

\section{Acknowledgements}

279 This study is part of an on-going PhD project and O.J.G is funded by the BBSRC (Grant code $280 \mathrm{BB} / \mathrm{K} 012770 / 1)$. The authors would like to express their thanks to the estate owners and the 281 Gamekeepers for use of the sites and the Game and Wildlife Conservation Trust for use of facilities.

\section{References}

284 Allander, K., \& Bennett, G. F. (1995). Retardation of breeding onset in Great Tits (Parus major) by 285 blood parasites. Funct. Ecol, 677-682.

287 Anderson, R. M., \& May, R. M. (1978). Regulation and stability of host-parasite population 288 interactions: I. Regulatory processes. J. Anim. Ecol. 219-247. 
Anderson, R. M. 1995. Evolutionary pressures in the spread and persistence of infectious agents in 291 vertebrate populations. Parasitol. 111, S15-S31.

Atkinson, C.T., Thomas, N.J., Hunter, B. 2008. Parasitic Diseases of Wild Birds. Wiley-Blackwell: 294 Iowa, USA.

Breitenbach, R. P., \& Meyer, R. K. 1959. Effect of incubation and brooding on fat, visceral weights and body weight of the hen pheasant (Phasianus colchicus). Poult. Sci. 38, 1014-1026.

Chastel, O., Weimerskirch, H., \& Jouventin, P. 1995. Body condition and seabird reproductive performance: A study of three Petrel species. Ecol. 76, 2240-2246.

Delahay, R. J., Speakman, J. R., \& Moss, R. 1995. The energetic consequences of parasitism: effects of a developing infection of Trichostrongylus tenuis (Nematoda) on red grouse (Lagopus lagopus scoticus) energy balance, body weight and condition. Parasitol. 110, 473-482.

Draycott, R. A., Parish, D. M., Woodburn, M. I., \& Carroll, J. P. 2002. Spring body condition of hen pheasants Phasianus colchicus in Great Britain. Wild. Biol. 8, 261-266.

Draycott, R.A.H., Parish, D.M.B., Woodburn, M.I.A., Carroll, J.P. 2000. Spring survey of the parasite Heterakis gallinarum in wild-living pheasants in Britain. Vet. Rec. 147, 245-246. 
312 Draycott, R.A.H., Woodburn, M.I.A., Ling, D.E., Sage, R.B. 2006. The effect of an indirect 313 anthelmintic treatment on parasites and breeding success of free-living pheasants (Phasianus 314 colchicus). J. Helminthol. 80, 409-415.

316 Drent, R. H., \& Daan, S. 1980. The Prudent Parent: Energetic Adjustments in Avian Breeding 1). 317 Ardea. 68, 225-252.

319 Dunn A.M., Torchin M.E., Hatcher M.J., Kotanen P.M., Blumenthal D.M., Byers J.E., Coon C.A.C., 320 Frankel V.M., Holt R.D., Hufbauer R.A., Kanarek A.R., Schierenbeck K.A., Wolfe L.M., Perkins 321 S.E. 2012. Indirect effects of parasites in invasions. Funct. Ecol. 26, 1262-1274

323 Fernando, M.A., Stockdale, P.H.G., Remmler, O. 1971. The route of migration, development and 324 pathogenesis of Syngamus trachea (Motagu, 1811), Chapin 1925, in Pheasants. J. Parasitol. 57, 107325116.

327 Gethings, O. J., Sage, R. B., \& Leather, S. R. 2015. Spatio-temporal factors influencing the 328 occurrence of Syngamus trachea within release pens in the South West of England. Vet. Parasitol. $329207,64-71$. 
331 Gethings, O. J., Sage, R. B., \& Leather, S. R. 2016. Density-dependent regulation of fecundity in 332 Syngamus trachea infrapopulations in semi-naturally occurring ring-necked pheasants (Phasianus colchicus) and wild Carrion Crows (Corvus corone). Parasitol. 143, 716.

335 Granoth-Wilding, H.M.V., Burthe, S.J., Lewis, S., Herborn, K.A., Takahashi, E.A., Daunt, F., 336 Cunningham, E.J.A. 2005. Indirect effects of parasitism: costs of infection to other individuals can be 337 greater than direct costs borne by the host. Proc. Roy. Soc: B. 282. 338 http://dx.doi.org/10.1098/rspb.2015.0602.

340 Hamilton, W.D. \& Zuk, M. 1982. Heritable true fitness and bright birds: A role for parasites? $341 \quad$ Science. 218, 384-387.

343 Holand, H., Jensen, H., Tufto, J., Pärn, H., Sæther, B. E., \& Ringsby, T. H. 2015. Endoparasite 344 Infection Has Both Short-and Long-Term Negative Effects on Reproductive Success of Female 345 House Sparrows, as Revealed by Faecal Parasitic Egg Counts. PloS. 10, e0125773.

Hudson, P.J. 1986. The effect of a parasitic nematode on the breeding production of Red Grouse. J. Anim. Ecol. 55, 85-92.

Hudson, P.J., Newborn, D. \& Dobson, A.P. 1992. Regulation and stability of a free-living host351 parasite system - Trichostrongylus tenuis in red grouse. I. Monitoring and parasite reduction experiments. J. Anim. Ecol, 61, 477-486. 
354 Hwang, J. C. 1964. Hemogram of turkey poults experimentally infected with Syngamus trachea. 355 Avian. Dis. 8, 380-390.

356

357 Irvine, R. J. 2006. Parasites and the dynamics of wild mammal populations. Anim. Sci. 82, 775-781. 358 doi:10.1017/ ASC2006106

360 Irvine, R. J., Corbishley, H., Pilkington, J. G., \& Albon, S. D. 2006. Low-level parasitic worm 361 burdens may reduce body condition in free-ranging red deer (Cervus elaphus). Parasitol. 133, 465362475.

363

364 Jones, P. J., \& Ward, P. 1976. The level of reserve protein as the proximate factor controlling the 365 timing of breeding and clutch- size in the red- billed Quelea (Quelea quelea). Ibis. 118, 547-574.

366

367 Leif, A.P. 1994. Survival and reproduction of wild and pen-reared ring-necked pheasant hens. J 368 Wildl. Manage . 58, 501-506.

369

370 Millán, J., C. Gortazar, P. Tizzani, and F. J. Buenestado. 2002. Do helminths increase the 371 vulnerability of released pheasants to fox predation? J. Helminthol. 76, 225-229. 
373 Moss, R. \& Watson, A. 2001. Population cycles in birds of the grouse family (Tetraonidae). Adv. 374 Ecol. Res. 32, 53-111.

376 Nevarez, J.G., Gamble, K.C., Tully, T.N. 2002. Syngamus trachea infection in two red and yellow 377 barbets Trachyphonus erythocephalus. J. Avian. Med. Surg. 16, 31-33.

379 Newborn, D. \& Foster, R. 2002. Control of Parasite Burdens in Wild Red Grouse Lagopus lagopus 380 scoticus through the Indirect Application of Anthelmintics . J. Anim. Ecol. 39, 909-914.

382 Sage, R. B., Putaala, A., \& Woodburn, M. I. 2002. Comparing growth and condition in post release 383 juvenile common pheasants on different diets. Poult. Sci. 81, 1199-1202.

385 Shutler, D., Alisauskas, T. \& McLaughlin, J.D. 2012. Associations between body composition and 386 helminths of lesser snow geese during winter and spring migration. Int. J. Parasitol. 42, 755-760.

388 Tompkins, D.M. \& Begon. M. 1999. Parasites can regulate wildlife populations. Parasitol. Today. 15, $389 \quad 311-316$.

391 Tompkins, D.M., Greenman, J.V., Hudson, P.J. 2000. Differential impact of a shared nematode 392 parasite on two gamebird hosts: implications for apparent competition. Parasitol. 122, 187-193. 
394 Verhulst, S. Dieleman, S.J. \& Parmentier, H.K. 1999. A tradeoff between immunocompetence and 395 sexual ornamentation in domestic fowl. Proc. Nat. Acad. Sci. 96, 4478-4481.

397 Villanúa, D., Acevedo, P., Toledo, R., Höfle, U., Rodríguez, O., \& Gortázar, C. 2006. Changes in 398 parasite transmission stage excretion after pheasant release. Journal of helminthology. 80, 313-318.

400 Watson, M.J. 2013. What drives population-level effects of parasites? Meta-analysis meets life401 history. Int. J. Parasitol. Parasites. Wild. 2, 190-196.

403 Wójcik, A. R., Wasilewski, I., Grygon-Franckiewicz, B., Zbikowska, E. 1999. Economic losses in 404 pheasant breeding evoked with endoparasites. Wiad. Parazyt., 45, 363 - 368 (In Polish).

406 Woodburn, M., Sage, R.B. \& Carroll, J.P. 2002. The efficacy of a technique to control parasitic 407 worm burden in pheasants (Phasianus colchicus) in the wild. Z. JAGDWISS. 48, 364-372.

409 Yom-Tov, Y. 2001. Global warming and body mass decline in Israeli passerine birds. Proc. Roy Soc. 410 B. $268,947-952$. 